\title{
DEVELOPMENT OF AN ELECTROSTATICALLY CLEAN SOLAR ARRAY PANEL ${ }^{\dagger}$
}

\author{
Theodore G. Stern and Duane Krumweide, Composite Optics, Inc., San Diego, CA 92121 \\ Edward Gaddy, NASAGoddard Space Flight Center, Greenbelt, MD \\ Ira Katz, Maxwell Technologies, Inc., San Diego, CA 92138
}

\begin{abstract}
The results of design, analysis, and qualification of an Electrostatically Clean Solar Array (ECSA) panel are described. The objective of the ECSA design is to provide an electrostatic environment that does not interfere with sensitive instruments on scientific spacecraft. The ECSA design uses large, ITO-coated coverglasses that cover multiple solar cells, an aperture grid that covers the intercell areas, stress-relieved interconnects for connecting the aperture grid to the coverglasses, and edge clips to provides an electromagnetically shielded enclosure for the solar array active circuitry. Qualification coupons were fabricated and tested for photovoltaic response, conductivity, and survivability to launch acoustic and thermal cycling environments simulating LEO and GEO missions. The benefits of reducing solar panel interaction with the space environment are also discussed.
\end{abstract}

\section{INTRODUCTION}

Certain missions require electrostatically clean solar array (ECSA) panels to establish a favorable environment for the operation of key scientific instruments. Current technology solar arrays have exposed electrical circuitry that interacts with the ambient plasma. This interaction affects the floating potential and particle trajectories surrounding the spacecraft, and so may influence scientific mission readings. Solar arrays with exposed conductors can both introduce and absorb current from the surrounding environment, and affect the shape of the plasma sheath that typically surrounds a solar array in earth orbit.

Electrostatically clean solar arrays are generally used only on spacecraft that measure fields and particles. The array and the rest of the spacecraft's outer surface are maintained closely to a uniform potential and at about the same potential as space plasma. This insures that the spacecraft does not alter the quantities it measures: electric and magnetic fields and particle momentum and energy. Early on, these arrays merely had indium tin oxide (ITO) coated covers that were grounded to spacecraft structure. As scientists developed more accurate experiments and needed better electrostatic performance, the arrays were improved to present the same potential to the plasma over their entire surface including the spaces

${ }^{t}$ This work was sponsored by the National Aeronautics and Space Administration under Contract \#NAS5-99236 between the cells, and to completely shield sources of array voltage and current from the plasma.

Goddard Space Flight Center (GSFC) and other organizations have flown electrostatically clean solar arrays for well over twenty years. Nonetheless, only a few such arrays have flown; and, those that have flown have frequently been problematic. This is primarily because it is difficult to shield array voltage on the interconnects and to configure the spaces between the cells as so that they are at the same potential as the rest of the spacecraft.

The earliest experience GSFC had with electrostatically clean solar arrays was on the International Sun Earth Explorer (ISEE)-A. The ISEE array did not require that the spaces between the solar cells be conductive or that the cell interconnects be insulated from the space environment. It was a simple matter of connecting one conductive cover to another and finally to spacecraft ground. By the time the ISEE array was being designed, A. E. G. Telefunken had developed a means of performing this task for another spacecraft. They deposited pads, composed of vapor deposited silver over vapor deposited palladium over vapor deposited titanium onto conductive covers. They then welded solar cell interconnects to the pads on adjacent covers and achieved the goal ISEE sought. Unfortunately, this method proved too expensive for ISEE. The conductive covers on ISEE were interconnected with wires fixed to the covers with conductive epoxy. Subsequent to environmental tests, the resistance between many of the epoxy joints and the conductive covers increased dramatically. The cause was probably a separation of the conductive elements in the epoxy as a result of thermal vacuum cycling. This cast doubt on the use of conductive epoxy as a means to interconnect conductive covers.

After ISEE, indium solder was used to make the interconnection between conductive covers and wires on several spacecraft. The solder presented difficulties of application and several percent of the joints would fail mechanically as a result of thermal cycling and other environmental exposure.

Recently, the GSFC purchased an electrostatically clean array for the Fast Auroral Snapshot (FAST) spacecraft. This array required the spaces between the solar cells be 
conductive and also that all conductive elements of the array, such as the solar cell interconnects, be insulated from the space environment. This meant that the delicate interconnects had to have an insulator over them and then a conductive surface over the insulator. FAST had covers that were on the order of .030 inch thick. A more typical cover thickness is .004 inch thick, which would probably preclude the use of the FAST components and methods. FAST used a conductive silicone to make electrical connection between the covers. When GSFC recently attempted to use this silicone to make connection to conductive-coated thermal control mirrors, the silicone was not available at a reasonable cost and delivery schedule. Finally, FAST used clips between the covers to form an equipotential surface between them. The clips were expensive to place and were prone to come off. Goddard also recently purchased arrays for the two Global Geospace Science spacecraft. This array was also relatively expensive to assemble.

Because of these experiences, GSFC recently embarked on a program with Composite Optics Inc. (COI) to obtain a generic method that would inexpensively and reliably provide for electrostatically clean arrays.

\section{ECSA DEVELOPMENT PROGRAM}

The objectives of this program are to design, develop and demonstrate an Electrostatically Clean Solar Array (ECSA) panel with continuous grounded shield surrounding the photovoltaic circuit, which has the following characteristics:

- Generates less than $0.1 \mathrm{~V}$ of potential between any two points on the panel surface in the presence of the space charged particle environment

- No exposure of solar panel active circuitry to the external environment

- No exposure of insulating surfaces to the charged particle environment

- Establishes an equipotential surface that can be grounded to the spacecraft through a connector

- Minimizes the number of parts, the increase in mass, the reduction in power, and the increase in cost of a solar panel as a result of components and modifications needed to achieve electrostatic cleanliness

- Compatible with any solar cell or coverglass used in conventional space solar panels.

To achieve these goals, we developed an ECSA solar panel design (shown in Figure 1) that uses:

- an array of Standard Power Modules (SPM's are multiple cells under a single conductive-coated coverglass),

- a Front Side Aperture (FSA) shield component that covers the areas between SPM's and around the edges, and

- an electrical bond between the coverglasses and the FSA shield that provides electrical continuity for the panel front and back sides, and insulation to assure electrical isolation between the FSA shield and the power circuit.

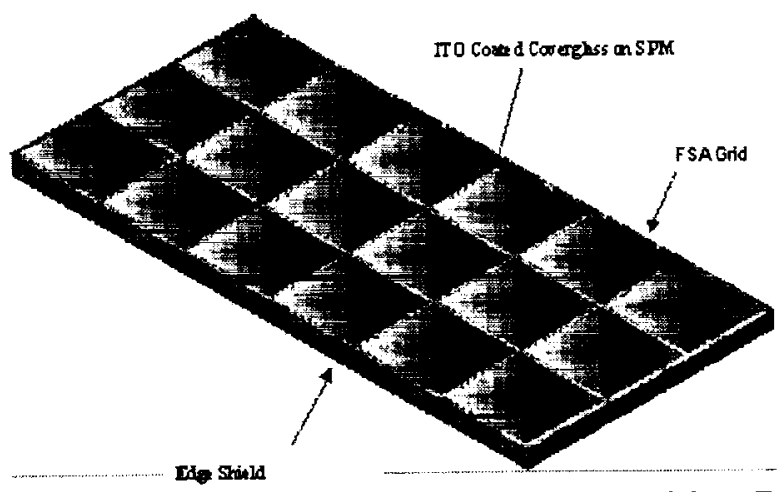

Figure 1. Basic Geometry of an ECSA Panel Using Front Side Aperture Grid and Edge Shields

\section{ECSA Conceptual Design Analysis}

To quantify the definition of electrostatically clean, an analysis was performed of how array conductivity and potentials affect the performance of particle and wave instruments. The maximum ram ion current density $(\sim 0.1$ micro ampere/cm2) in LEO was selected as the design goal for determining the required surface conductivity. The ion flux was chosen, as opposed to the electron current density, because there are enough electrons available to balance the smaller ion currents. The ITO coatings and other surface conductivities were sufficient to limit potential differences to $0.1 \mathrm{~V}$ in GEO for all charging environments both in sunlight and eclipse. This includes the case of electron collection on the array backside and photoemission off the coverglasses.

The $0.1 \mathrm{~V}$ is extremely conservative, and was chosen because it was achievable with the ECSA technology. The analysis showed that with the ECSA design, the solar array self generated voltages and collected plasma currents would change the solar array ground potential by less than $0.1 \mathrm{~V}$ in all orbits from LEO to GEO. We also showed that array generated potentials would perturb the ambient potentials by less than $0.1 \mathrm{~V}$ at distances greater than $0.1 \mathrm{~cm}$ from the array surface. The $0.1 \mathrm{~V}$ is comparable to electron temperatures in the ionosphere, and is the lowest charged particle energy. The $0.1 \mathrm{~cm}$ is much less than the distance between the array and any instrument.

Analysis of the ECSA design determined the voltages that might be incurred near the panel, even if the FSA does not seal the edges of the SPM's. A gap height of 20mils $(0.5 \mathrm{~mm})$ was used as a typical value achievable between the FSA and the SPM if a continuous bond to the edges of the coverglass was not used. A typical result is shown in Figure 2, which depicts a gap between the FSA and the coverglass of $0.5 \mathrm{~mm}$ and a $0.5 \mathrm{~mm}$ overhang. These data indicate that a small voltage is established near the gap area $(<0.9 \mathrm{~V})$, but that this voltage dissipates rapidly with distance away from the gap, and is in fact $<1 \mathrm{mV}$ at a distance greater than $1 \mathrm{~mm}$ from the panel surface. 


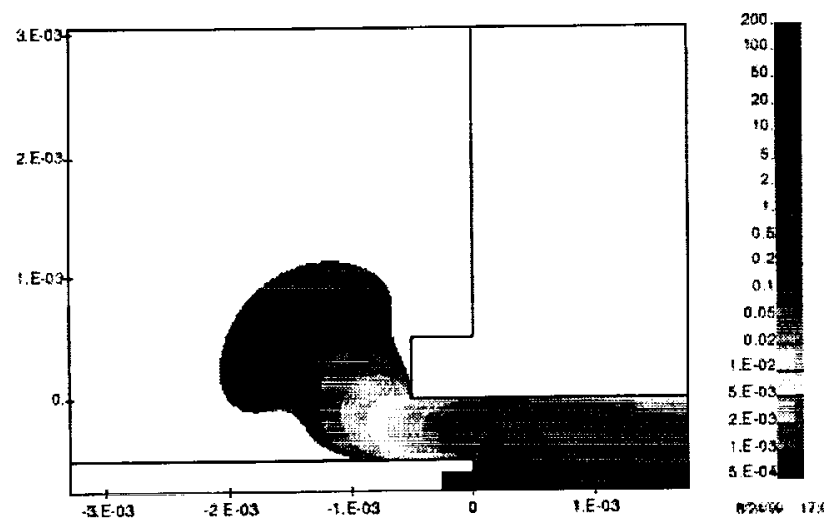

Figure 2. Typical electrostatic analysis result shows small voltage fields even with gaps under the FSA.

The analysis of maintaining equipotential on the ECSA panel surface looked at different ITO thickness values and resulting resistance, and determined the maximum voltage that could be established on the coverglass under exposure to the charged particle environment. The results of this analysis showed that an ITO coating with a resistivity of $3 \times 10 \mathrm{E}+4 \Omega /$ square or less would be needed to establish a potential of $<0.1 \mathrm{~V}$ (considered equipotential by agreement). This coating would be about $150 \mathrm{~A}$ thick. The analysis also determine a point-to-point resistance test criteria for establishing that sufficient conductivity had been achieved within the ITO coating and from the coating to the FSA grounded structure. This analysis considered various geometric configurations shown in Figure 3, and concluded that a measurement of less than 100kohms from the center of the coverglass to the structure would be sufficient to maintain the $0.1 \mathrm{~V}$ requirement under space conditions.

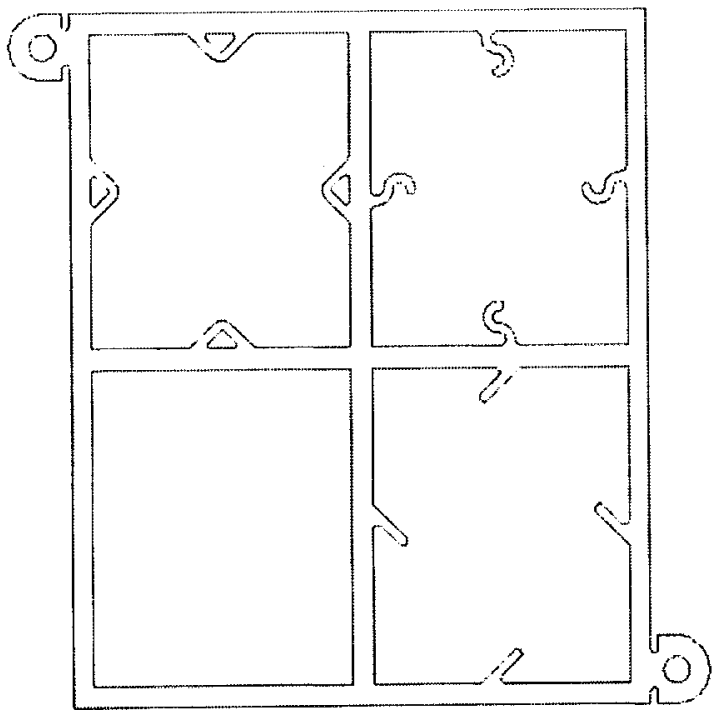

Figure 3. Layout of the Frontside Aperture Shield for the Qual Coupons.

\section{Qualification Coupons}

COI developed the design for qualification panel coupons using two different FSA bonding approaches and four different FSA-to-coverglass interconnecting schemes, one for each SPM aperture. The design of the FSA for the qualification coupons is shown in Figure 3 . The interconnects shown on the three apertures are connected to the coverglasses with conductive adhesive, using McGann Nusil CV2-2646 silver-filled silicone adhesive. The fourth aperture, which is shown as blank, uses beryllium copper contact fingers, electrically and mechanically bonded to the FSA, and spring-contacted to the coverglass. Two coupons were fabricated to test different structural bonding approaches - one used a silicone preform to bond the FSA to the panel, and the other used a film adhesive with embedded copper mesh in an attempt to improve electrical conductivity to the SPM. A completed qualification coupon is shown in Figure 4.

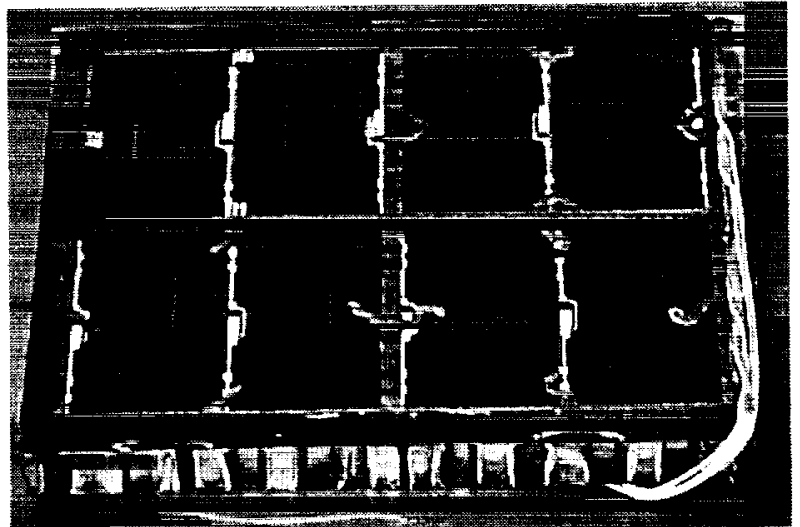

Figure 4. Qualification coupon using four coverglass interconnect approaches

Electrical I-V and resistance tests were performed on the qualification coupons prior to thermal cycling. These tests were repeated after exposure to the thermal cycling environment, which consisted of 200 cycles from $-180 \mathrm{C}$ to $35 \mathrm{C}$, representing a GEO thermal environment and 1000 cycles from $-90 \mathrm{C}$ to $90 \mathrm{C}$, representing a LEO thermal environment. These results are summarized in Table 1.

Table 1. Resistance from each aperture to panel ground.

\begin{tabular}{|l|r|r|r|}
\hline Interconnect type & $\begin{array}{l}\text { Before } \\
\text { Thermal } \\
\text { Cycling }\end{array}$ & $\begin{array}{l}\text { After } \\
\text { GEO } \\
\text { Cycles }\end{array}$ & $\begin{array}{l}\text { After } \\
\text { LEO } \\
\text { Cycles }\end{array}$ \\
\hline Slant & $33 \mathrm{k} \Omega$ & $12 \mathrm{k} \Omega$ & $50 \mathrm{k} \Omega$ \\
\hline Serpentine & $98 \mathrm{k} \Omega$ & $26 \mathrm{k} \Omega$ & $97 \mathrm{k} \Omega$ \\
\hline Diamond & $23 \mathrm{k} \Omega$ & $7 \mathrm{k} \Omega$ & $20 \mathrm{k} \Omega$ \\
\hline Be-Cu Contact Finger & $27 \mathrm{k} \Omega$ & $8 \mathrm{k} \Omega$ & $52 \mathrm{k} \Omega$ \\
\hline
\end{tabular}

Of the two bonding approaches, only the silicone bond had sufficient strength and resiliency to survive the thermal cycling environment. Although all four apertures, with their differing interconnect shapes, met the resistance requirement, the diamond interconnect configuration had 
the lowest resistance after cycling, and was chosen for inclusion into a full-size prototype panel.

\section{Prototype Full-Scale Panel}

A full-scale prototype panel was built (shown in Figure 5), which uses 48 SPM's ( 96 cells) connected in four series circuits. Dual bandgap solar cells were used with a typical room temperature AMO bare cell efficiency of better than $22 \%$. These cells were interconnected into strings of SPM's and laid down onto a graphite honeycomb substrate using conventional panel assembly technology.

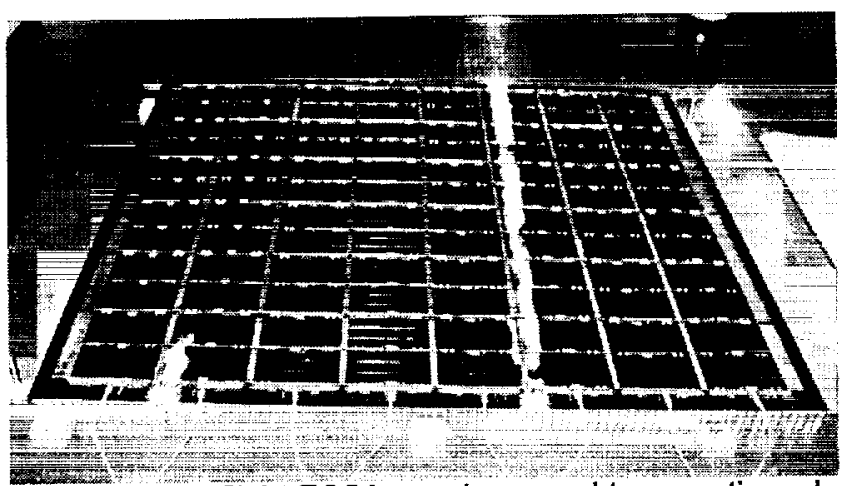

Figure 5. Protoflight ECSA panel exposed to acoustic and thermal cycling environments.

The prototype panel was tested for its performance and durability to a typical set of space solar panel environments, including launch acoustic environment and the same thermal cycle regime as for the qualification coupons. Measurements of mass and photovoltaic performance of the panel, as well as isolation and grounding, were taken on the prototype before and after application of the electrostatically clean components, before and after acoustic test, and before and after thermal cycling tests.

The mass measurements are summarized in Table 2, and show an increase of $6 \%$ from adding electrostatically clean features to this conventional array technology. Panel photovoltaic performance before and after adding EC components is summarized in Table 3 . Shadowing of the cells by the FSA, its interconnects and the conductive adhesive result in a decrease in current, and corresponding decrease in power and efficiency of $7 \%$. In addition, the packing factor of the ECSA panel is reduced by about $7 \%$ because of spacing needed to accommodate a robust FSA. In demonstrating the feasibility of the ECSA approach, we chose to fabricate components that were structurally robust. These performance figures do not account for any optimization that might minimize the reduction in output by, for example, making the members of the FSA framing much thinner, or the interconnects smaller, so as to improve packing factor and shadowing. Photovoltaic performance after acoustic and thermal environmental exposure was unaffected for all parameters in Table 3.
Table 2. Panel masses before and after addition of electrostatically clean components shows a $6 \%$ delta.

\begin{tabular}{|l|r|}
\hline Component & Mass \\
\hline Substrate & $711 \mathrm{~g}$ \\
\hline $\begin{array}{l}\text { Panel without EC components (FSA, edge clips, } \\
\text { FSA structural adhesive and conductive adhesive) }\end{array}$ & $1055 \mathrm{~g}$ \\
\hline Completed prototype panel & $1118 \mathrm{~g}$ \\
\hline
\end{tabular}

Table 3. Photovoltaic performance of the ECSA panel before and after adding ECSA specific components.

\begin{tabular}{|l|r|r|}
\hline Parameter & Before & After \\
\hline Voc & $58.78 \mathrm{~V}$ & $58.61 \mathrm{~V}$ \\
\hline Isc & $1.49 \mathrm{~A}$ & $1.40 \mathrm{~A}$ \\
\hline Pmax & $69.42 \mathrm{~W}$ & $64.33 \mathrm{~W}$ \\
\hline Vmp & $49.37 \mathrm{~V}$ & $49.26 \mathrm{~V}$ \\
\hline Imp & $1.41 \mathrm{~A}$ & $1.31 \mathrm{~A}$ \\
\hline FF & $79.1 \%$ & $78.2 \%$ \\
\hline Efficiency & $21.98 \%$ & $20.37 \%$ \\
\hline
\end{tabular}

Electrical grounding and isolation measurements taken before and after environmental exposure showed the ability of the ECSA approach to maintain equipotential on the panel surface by limiting surface point-to-point resistance measurements to less than $100 \mathrm{k} \Omega$. Some of the conductive adhesive bonds failred - these failures were attributed to inadequate surface preparation of the coverglass coating prior to conductive adhesive bond. Further testing is being performed to verify that proper surface preparation allows the panel to qualify to these thermal cycle environments.

\section{CONCLUSIONS AND RECOMMENDATIONS}

We have demonstrated the feasibility of achieving an ECSA panel using a minimum number of components. The resulting panel can achieve electrostatic cleanliness at a small penalty in mass, and with a modest reduction in power performance. The cost of modifying the panel should also be small, based on the simplicity of the design. Further optimization of the FSA should be undertaken with the objective of minimizing the penalty incurred for achieving electrostatic cleanliness.

References:

[1] E. M. Gaddy and J. A. Bass, Interconnecting Conductively Coated Coverslides, Proceedings of the Thirteenth Photovoltaic Specialists Conference, Vol. I. 1978 , p. 313.

[2] M. Kruer and J. Lyons, "The FAST Solar Array: Challenging Requirements, Novel Design," Proceedings of the First World Conference on Photovoltaic Energy Conversion, 1994, p. 1949.

[3] T. Spitzer, "The GGS Spacecraft, Solar Arrays for Space Physics," Proceedings of the Twenty-Fifth Photovoltaics Specialists Conference, 1996, p. 305. 


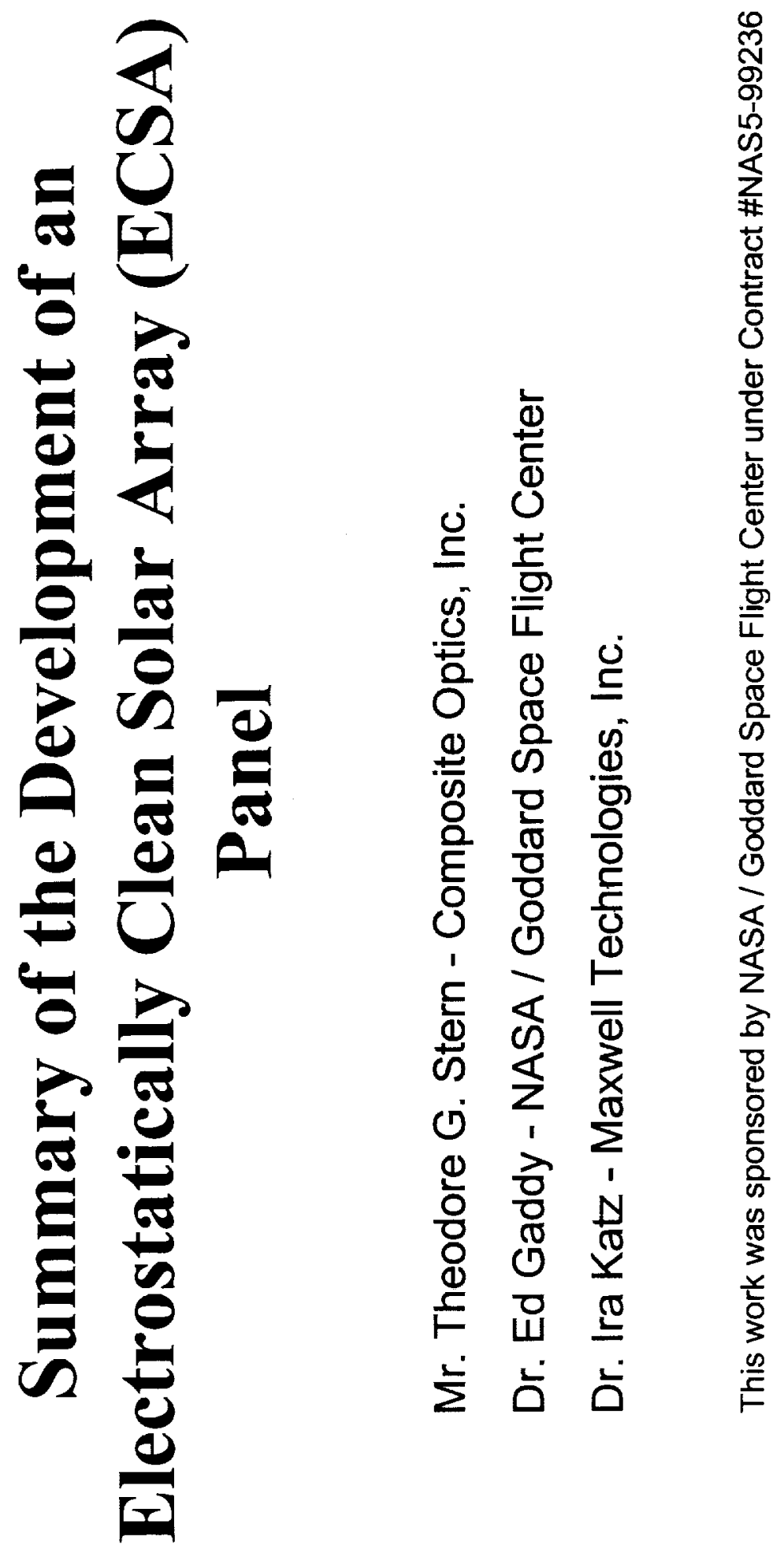

SəInฺnఘS - IOD 


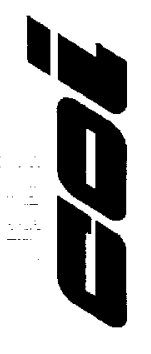

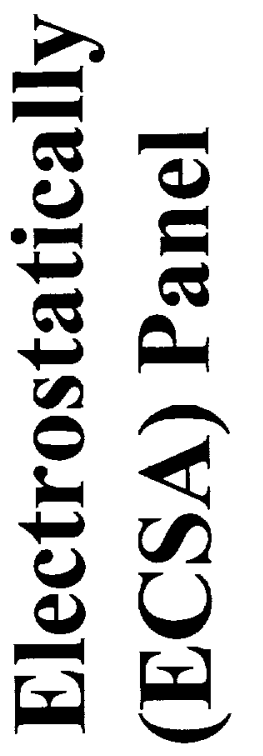

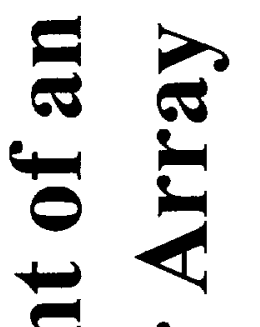

을 흥

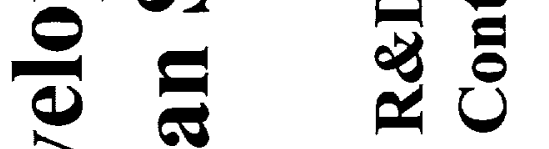

อั
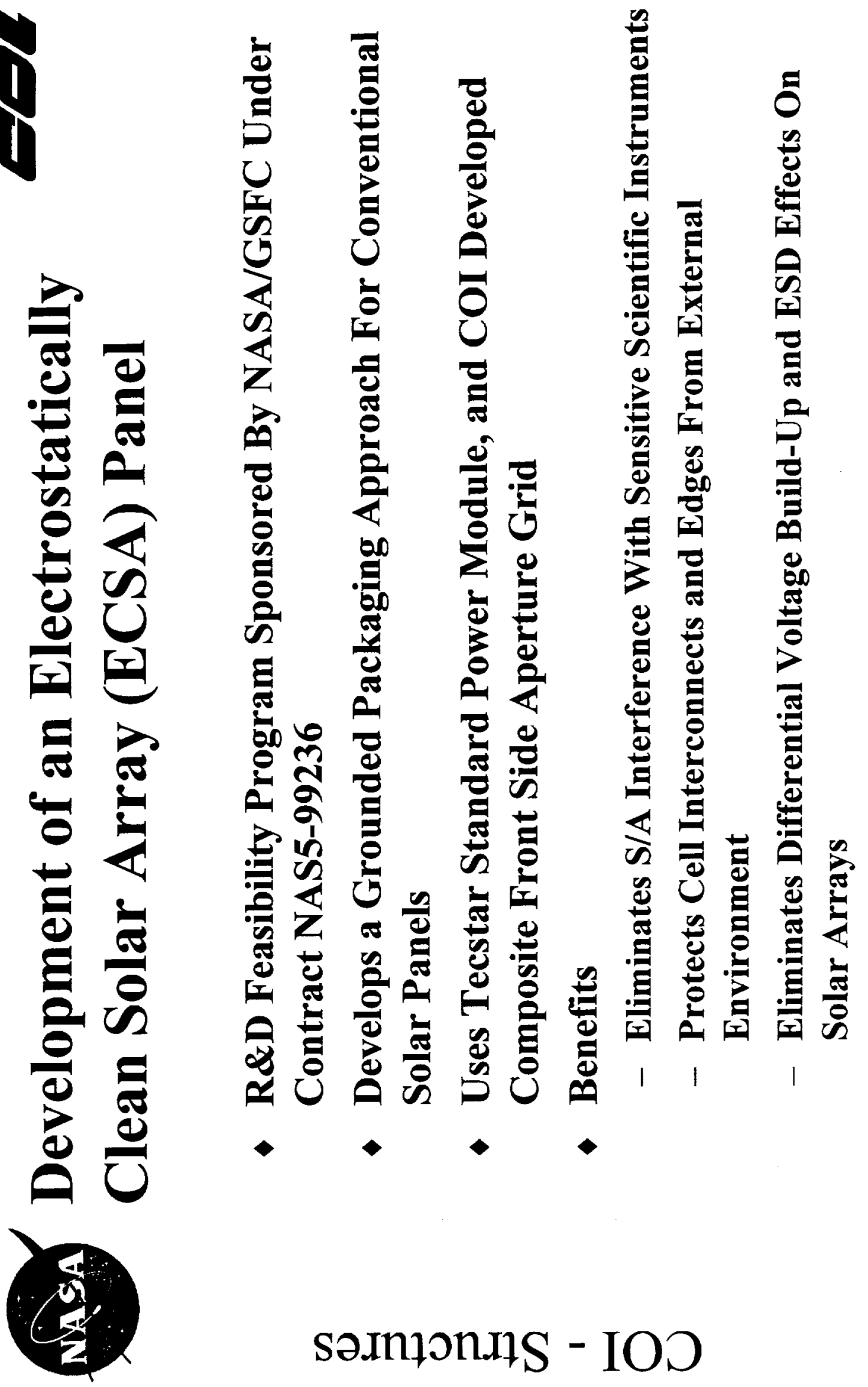

SəImฺnఘS - IOD 


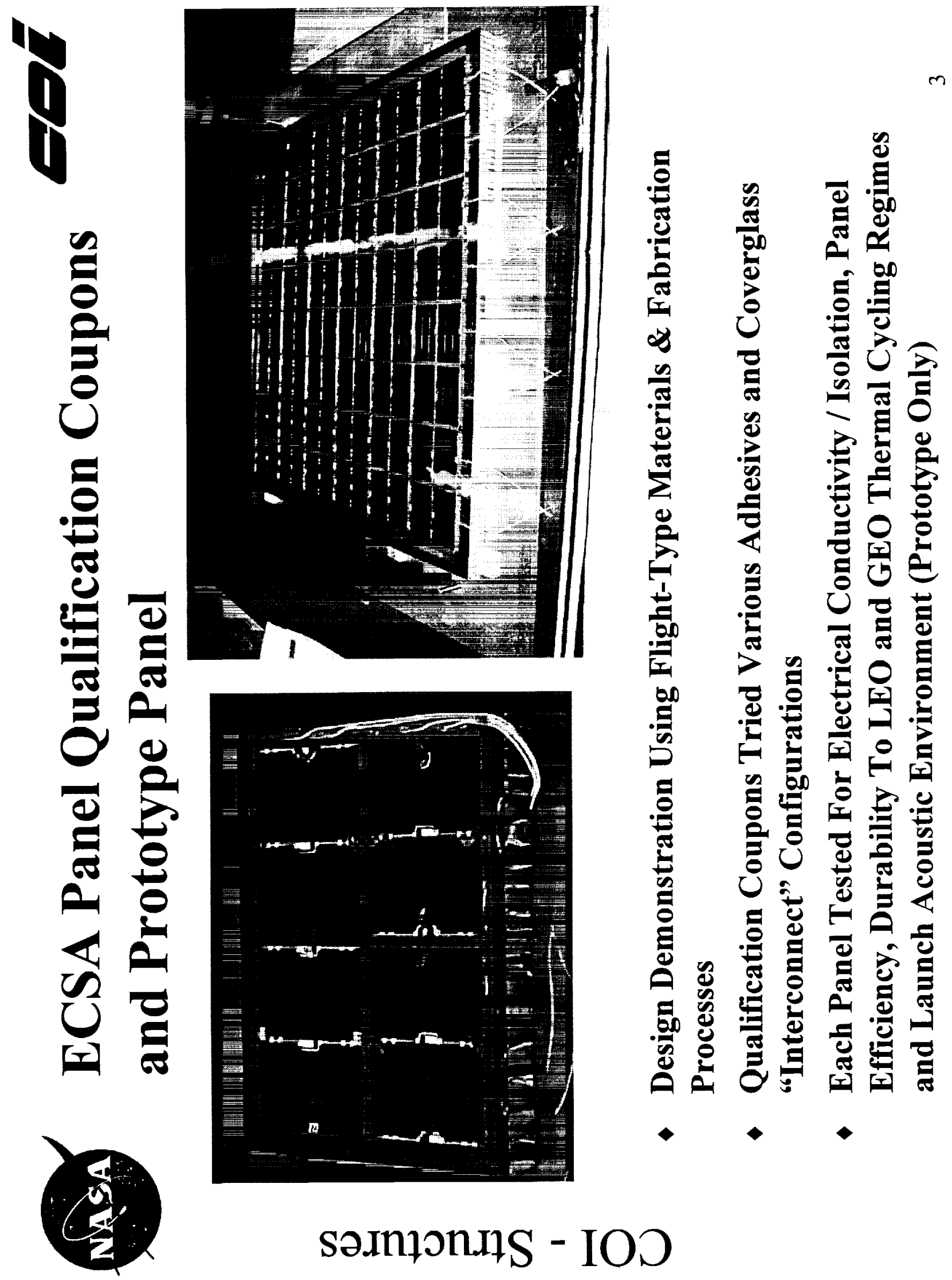



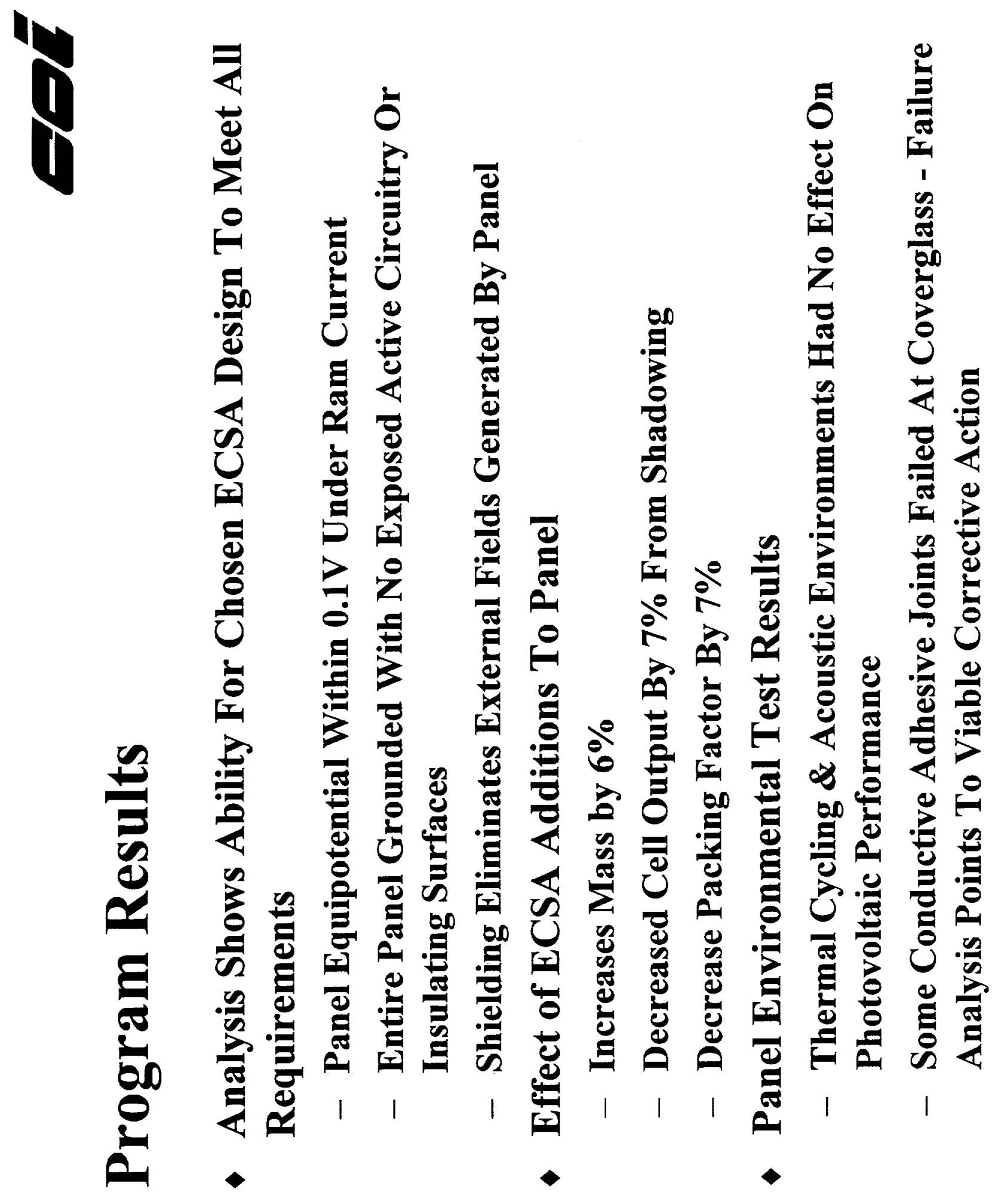

SวInฺฺIIS - IOD 

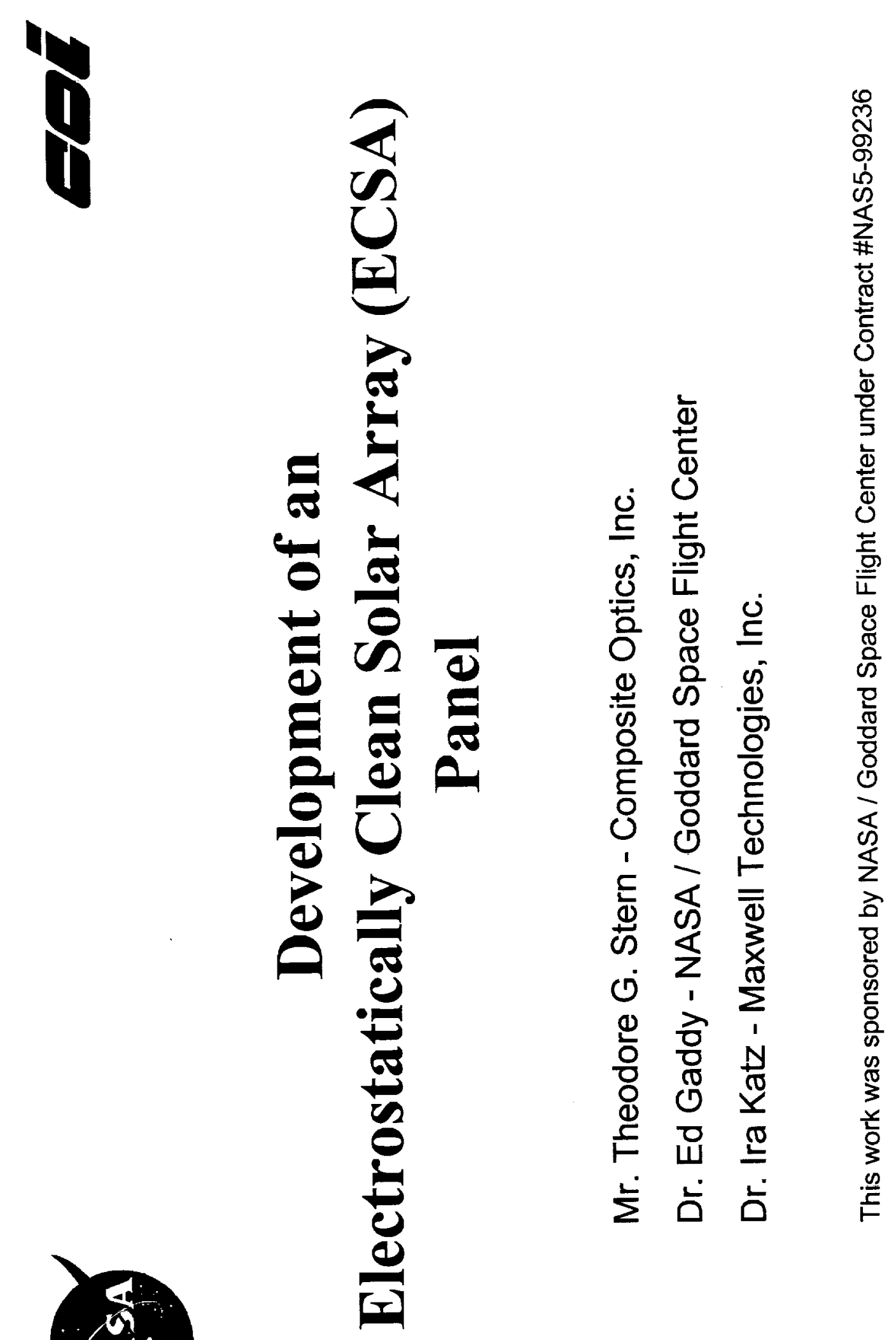

səInฺฺnIS - IOD 

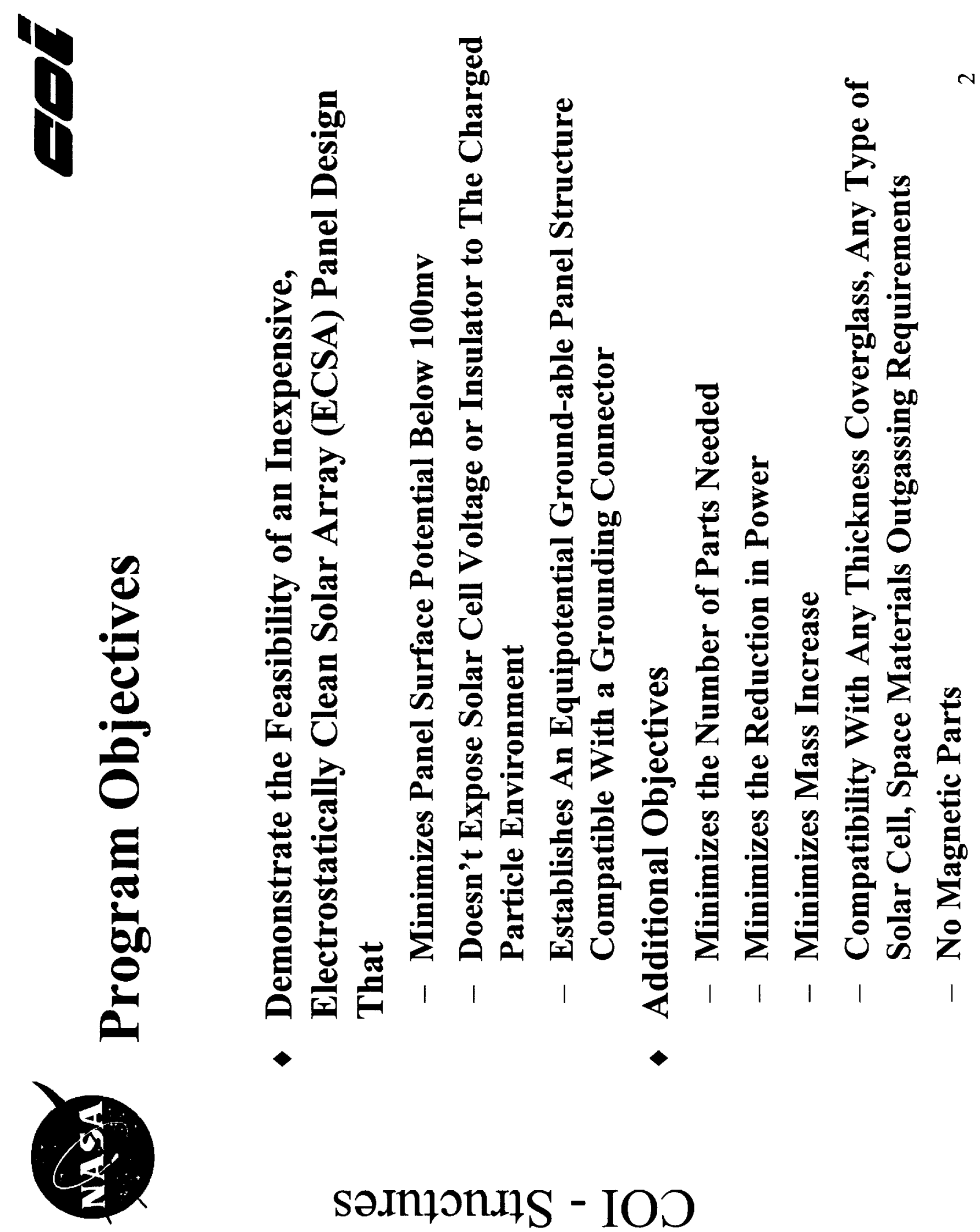

səInฺกıIS - IOD 

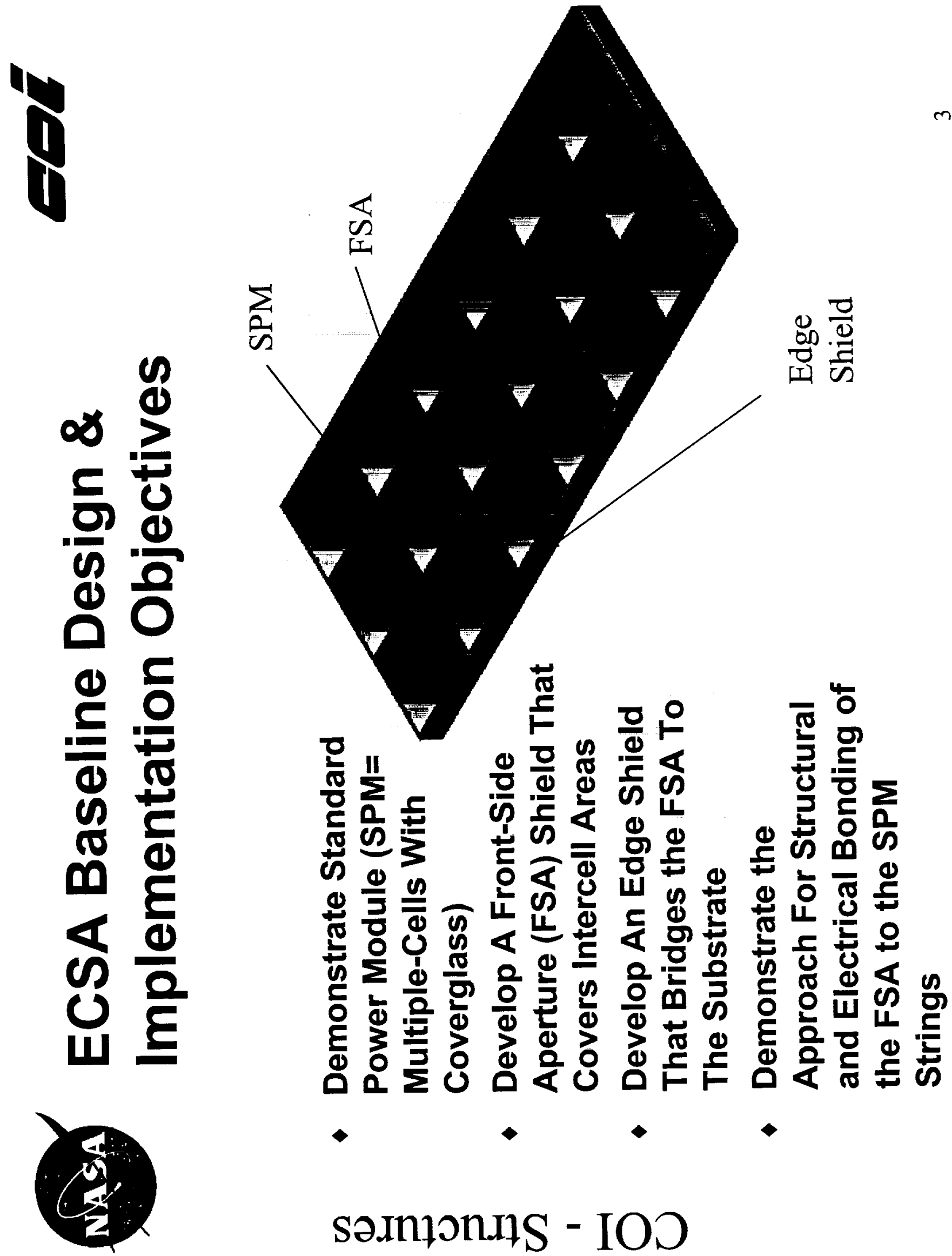


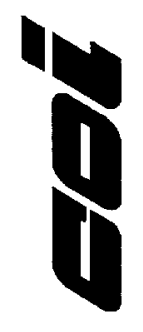

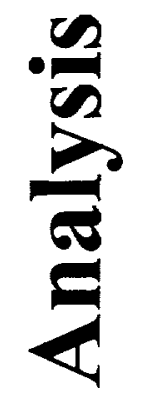
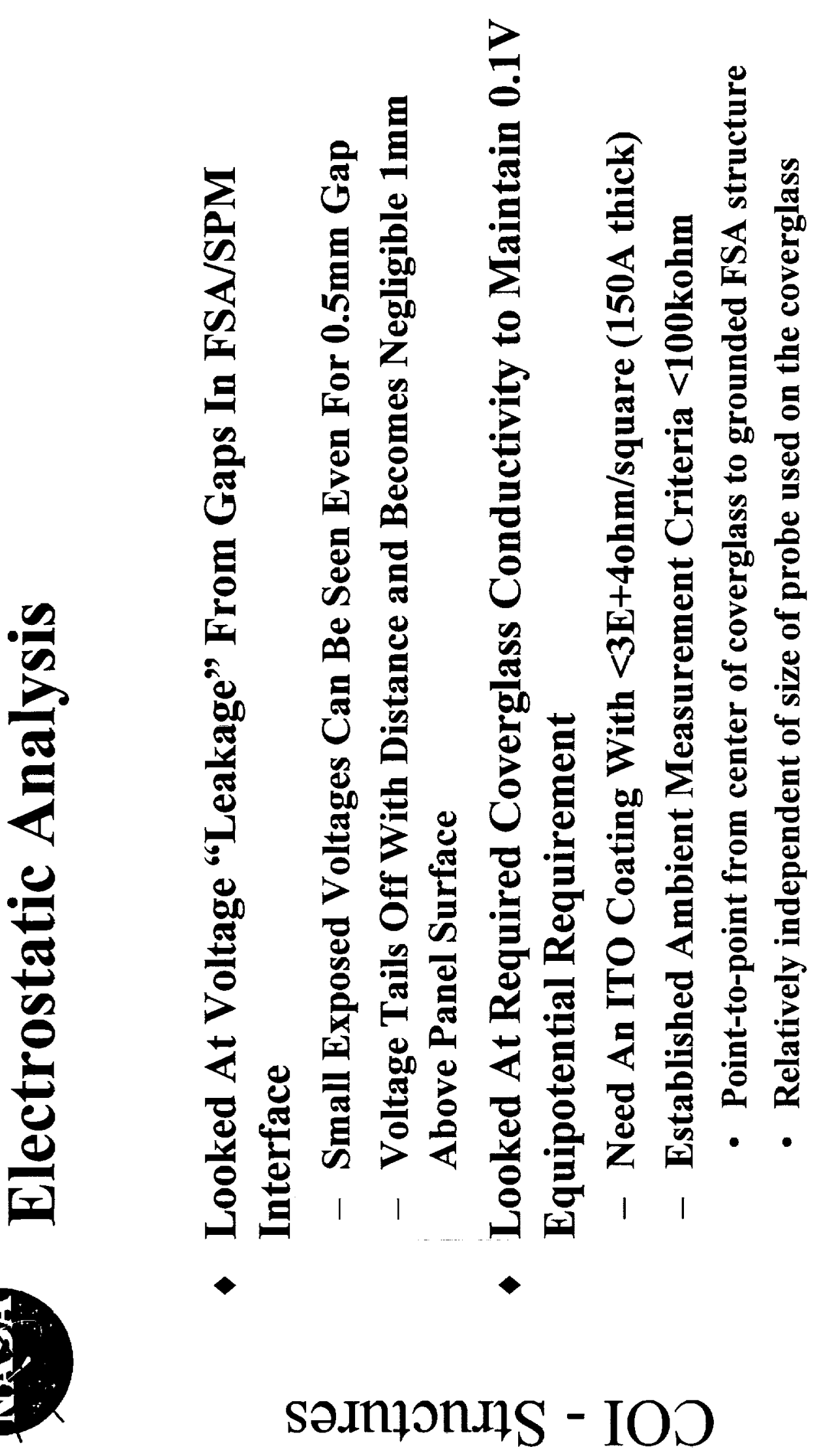


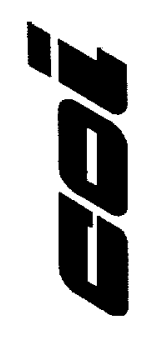

造
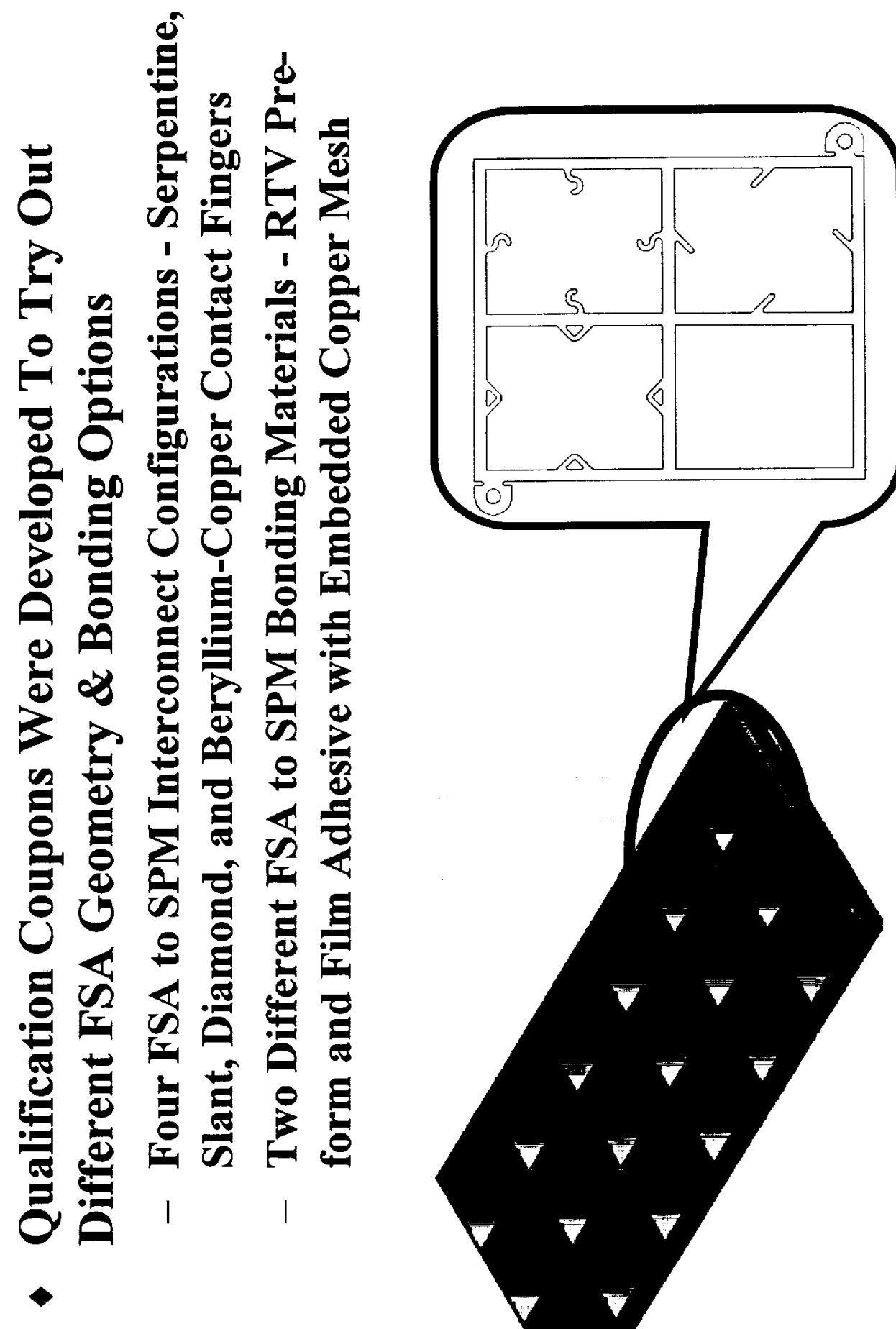

.60

\%

8

อ

0

ฮ

A

$\varangle$

$\mathcal{U}$

U

Ex

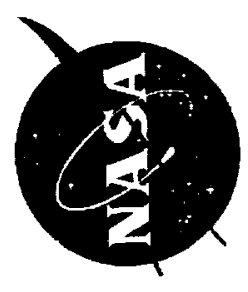

SวInฺฺฺIS - IOD 

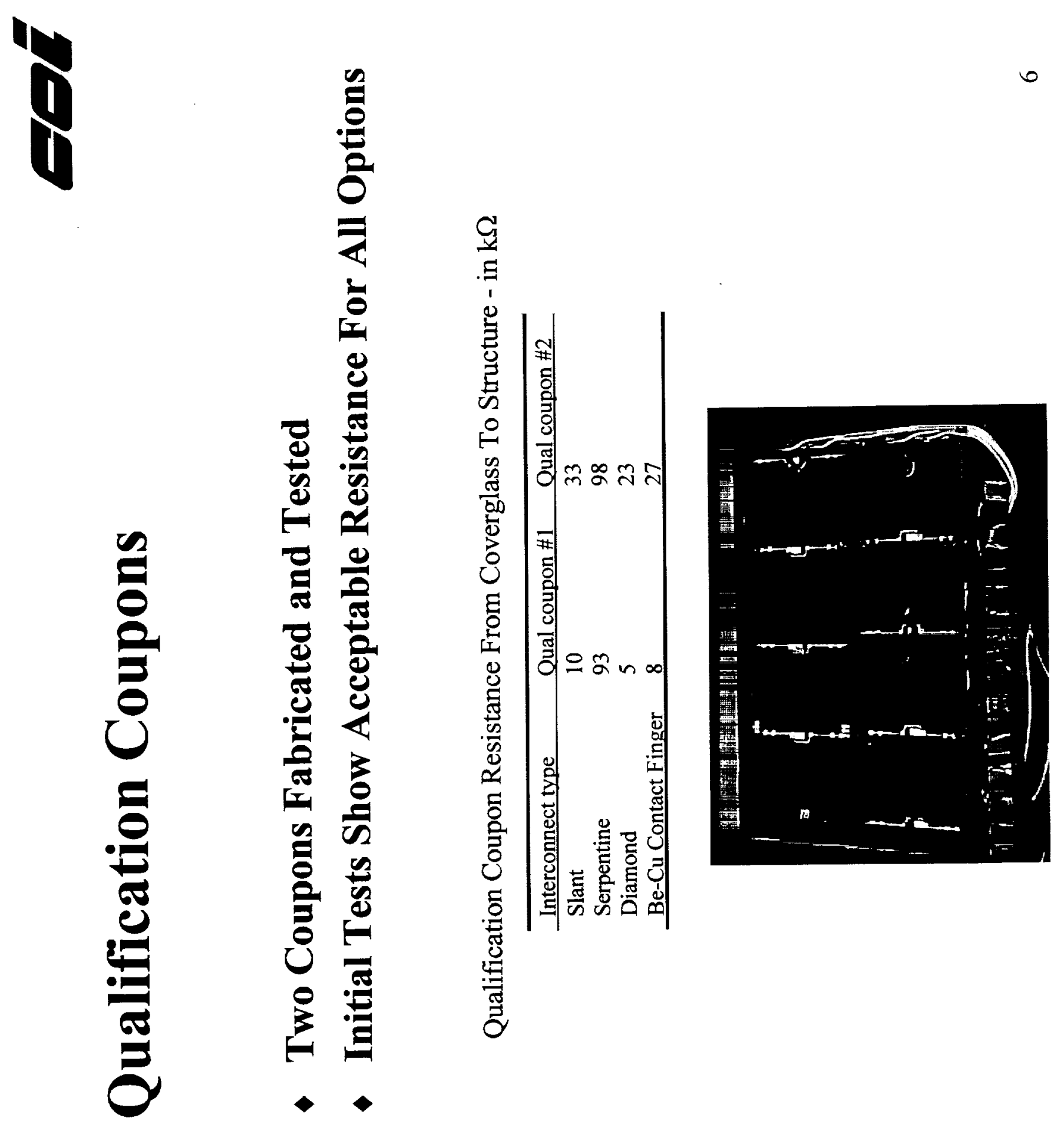

səInฺฺIIS - IOD 
2

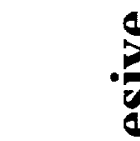

$\frac{1}{8}$

$\frac{g}{0}=$

$\forall \equiv \widehat{O}$

$\omega_{\infty} \quad \delta$

요용

$\sigma$ I 8

क

$\because \quad \bar{g} V$

a

- 20

$\sum_{0}^{\infty}$

$-60$

$\theta$

$\rightarrow$

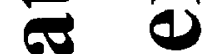

$e^{2}$

5

$\sum_{0}^{\infty}$

E

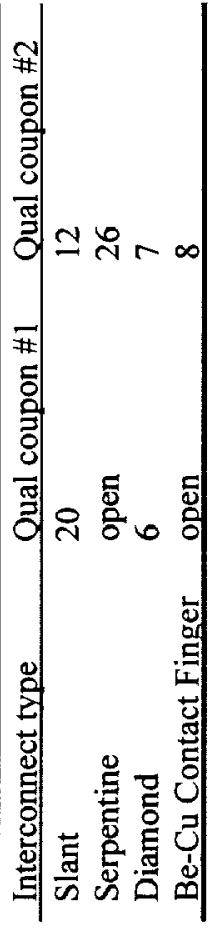

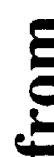

8

6)

E

c

e

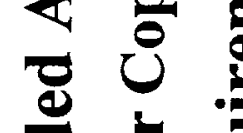

웅

80

음

9 舟

क 000

死

-

严突

宅

\#

e $\mid$ 我的向

8

고

ฮٍู

幽

$\mathrm{C}_{1}$

O 10

a 


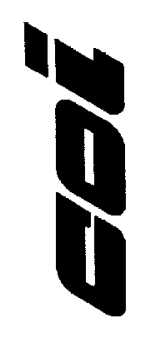

$\underset{8}{6}$
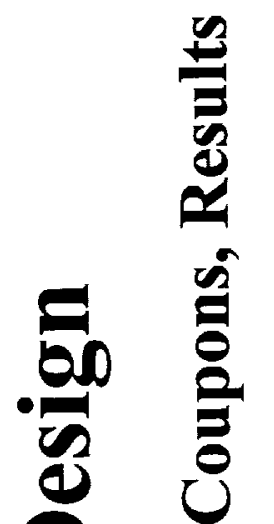

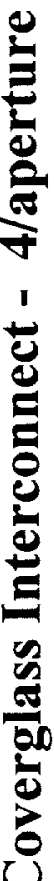

60 용

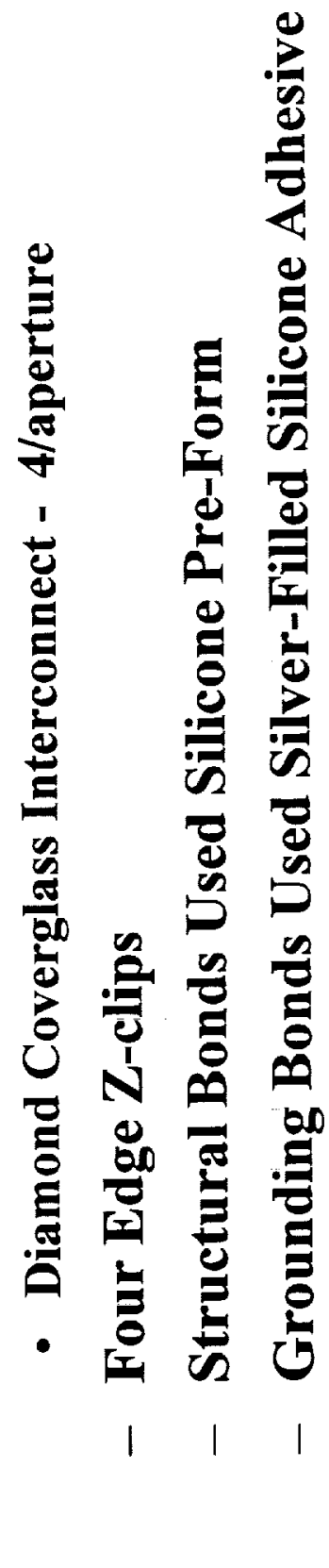

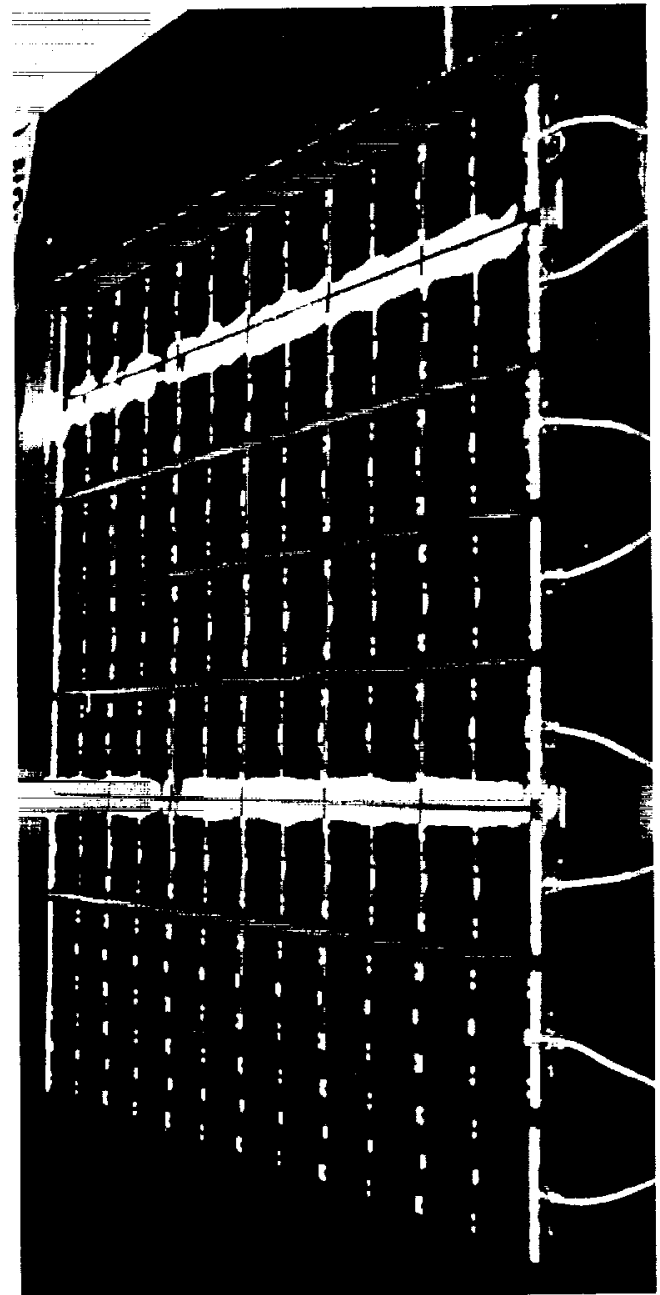

səInฺฺฺฺS - IOD 

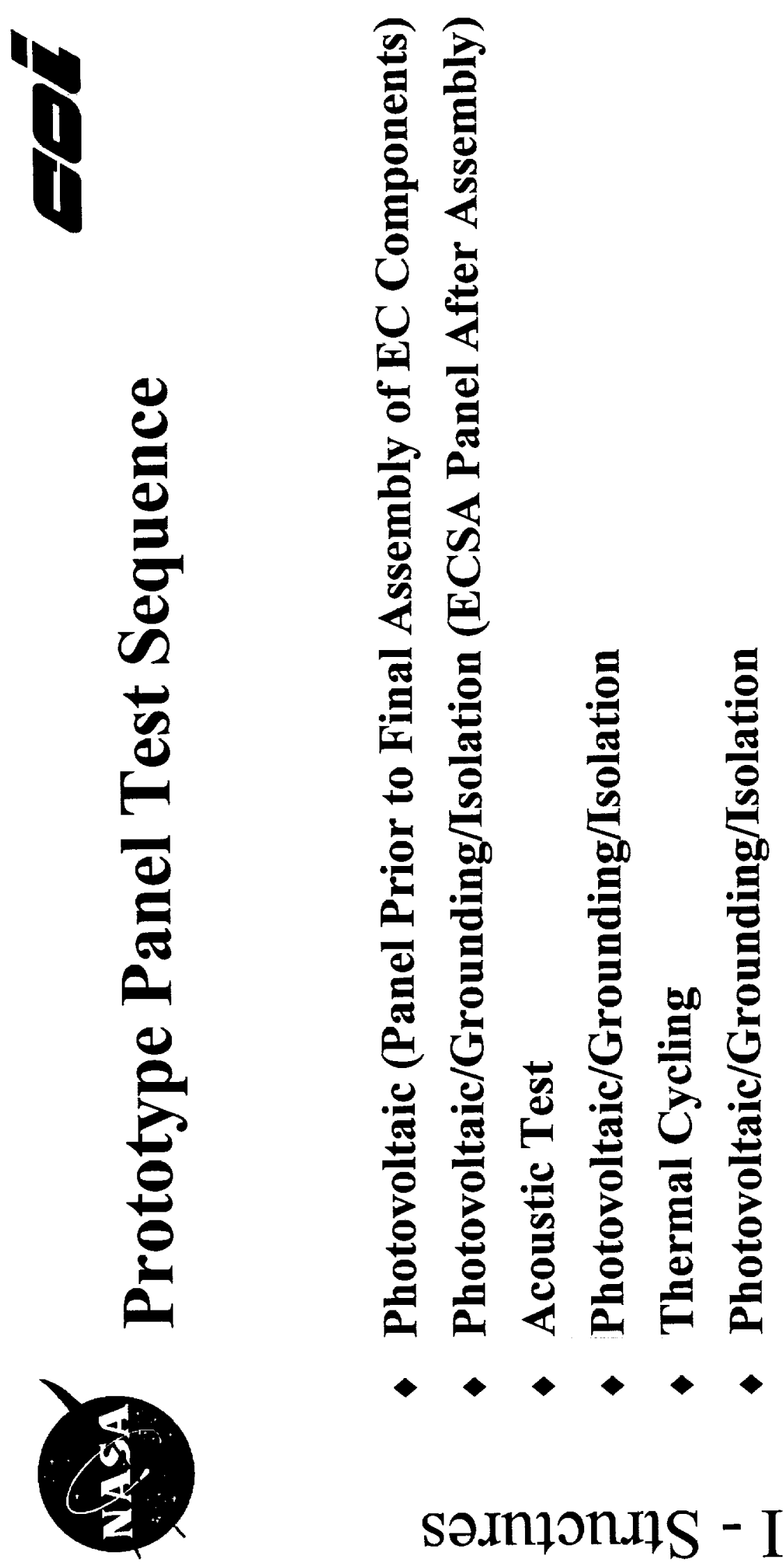


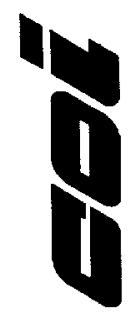

$\stackrel{\circ}{\circ}$

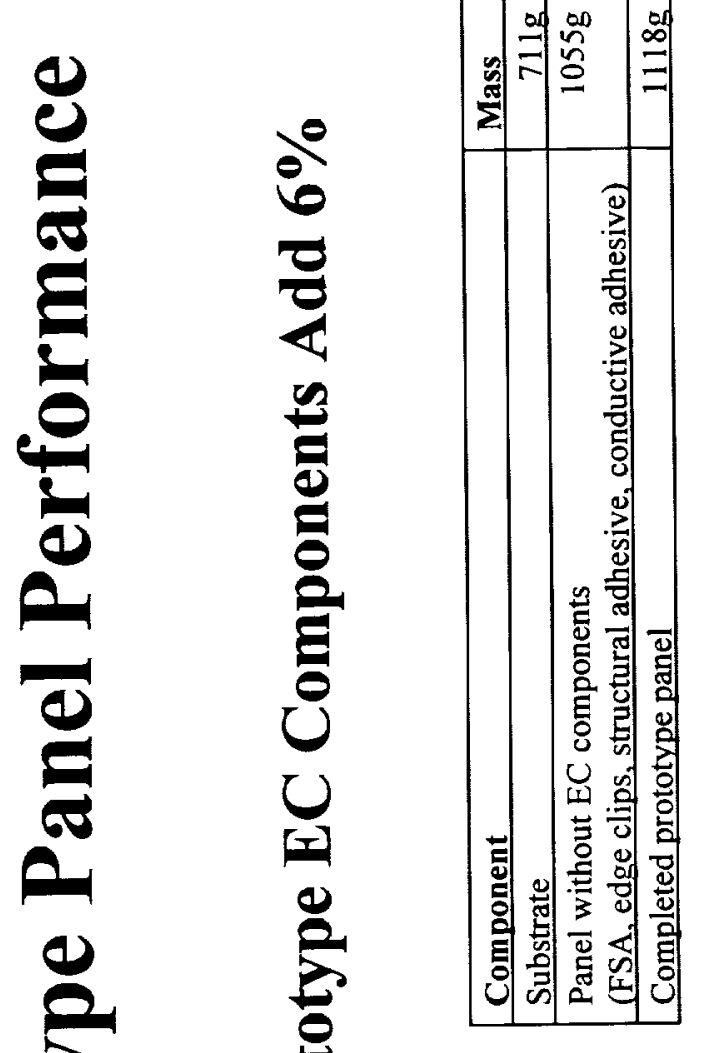

亘

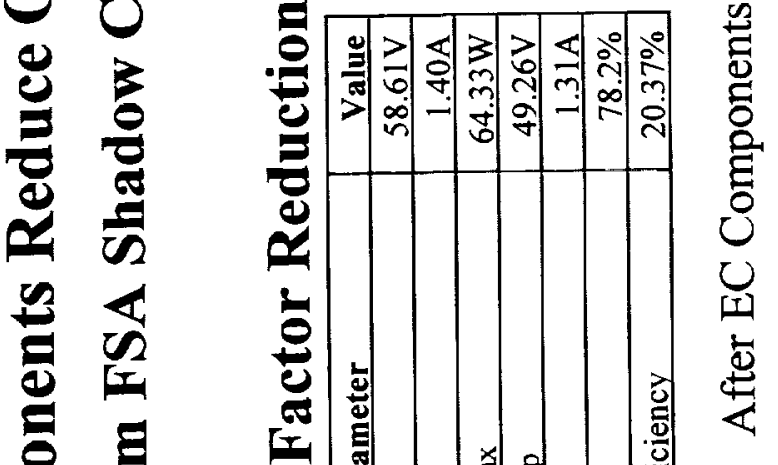

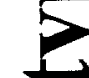

.

?

$\sum_{1}^{0}$

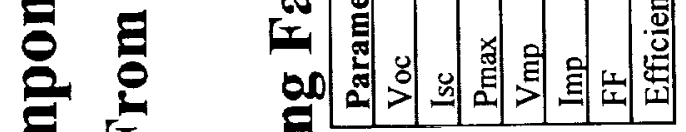

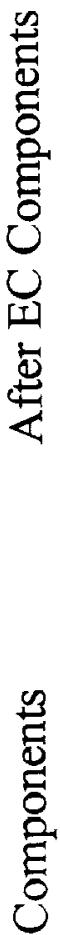

是运

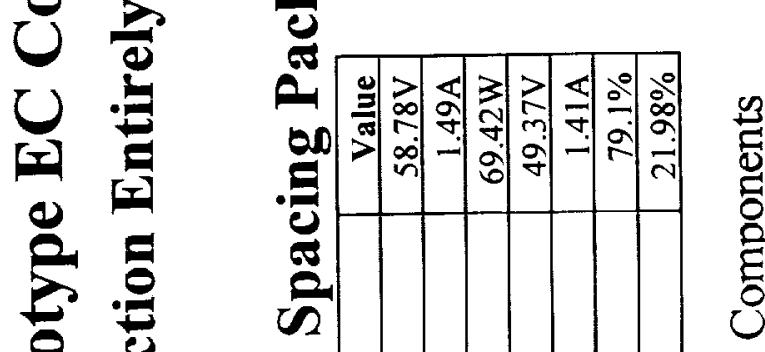

$\begin{array}{lll}0 & 0 & 0 \\ 0 & 0 & 0\end{array}$

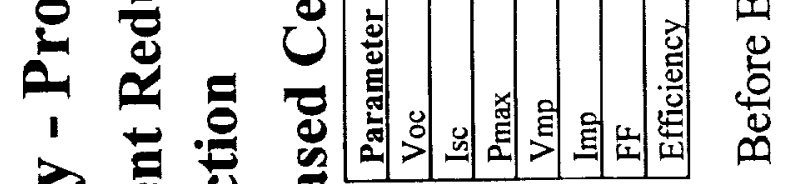

səImฺnIIS - IOD 

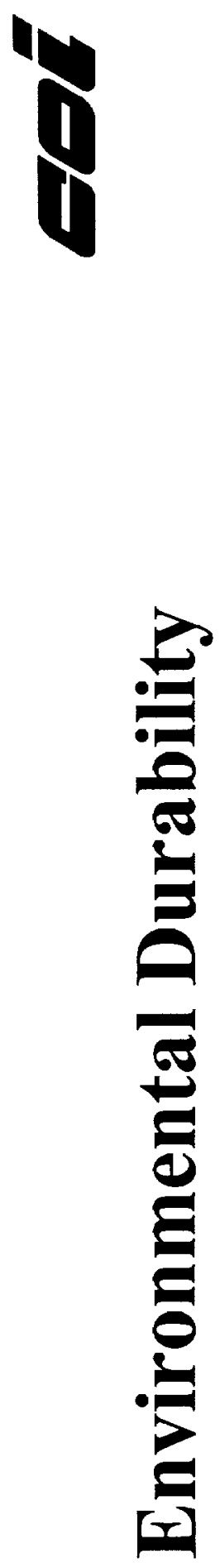
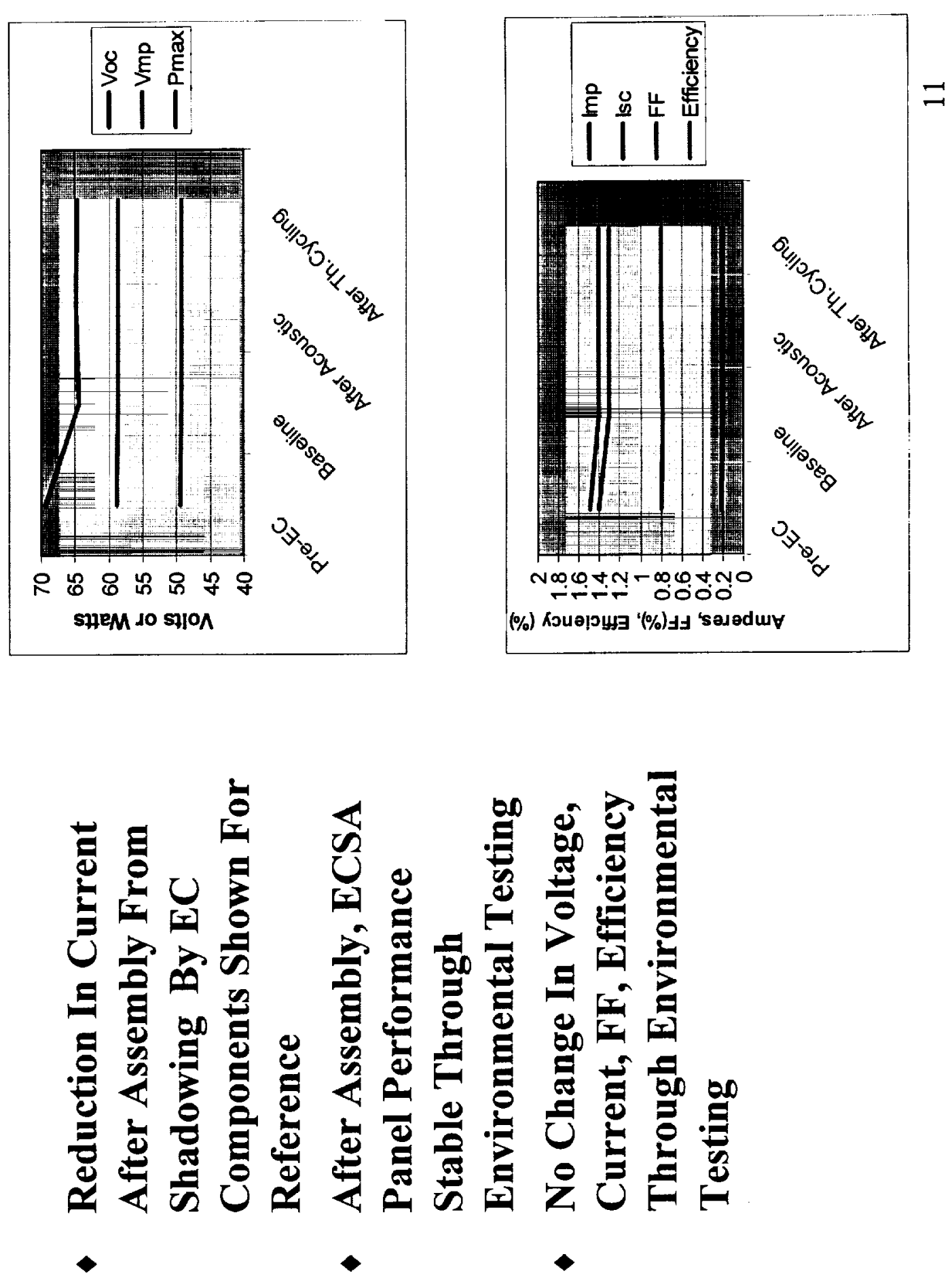

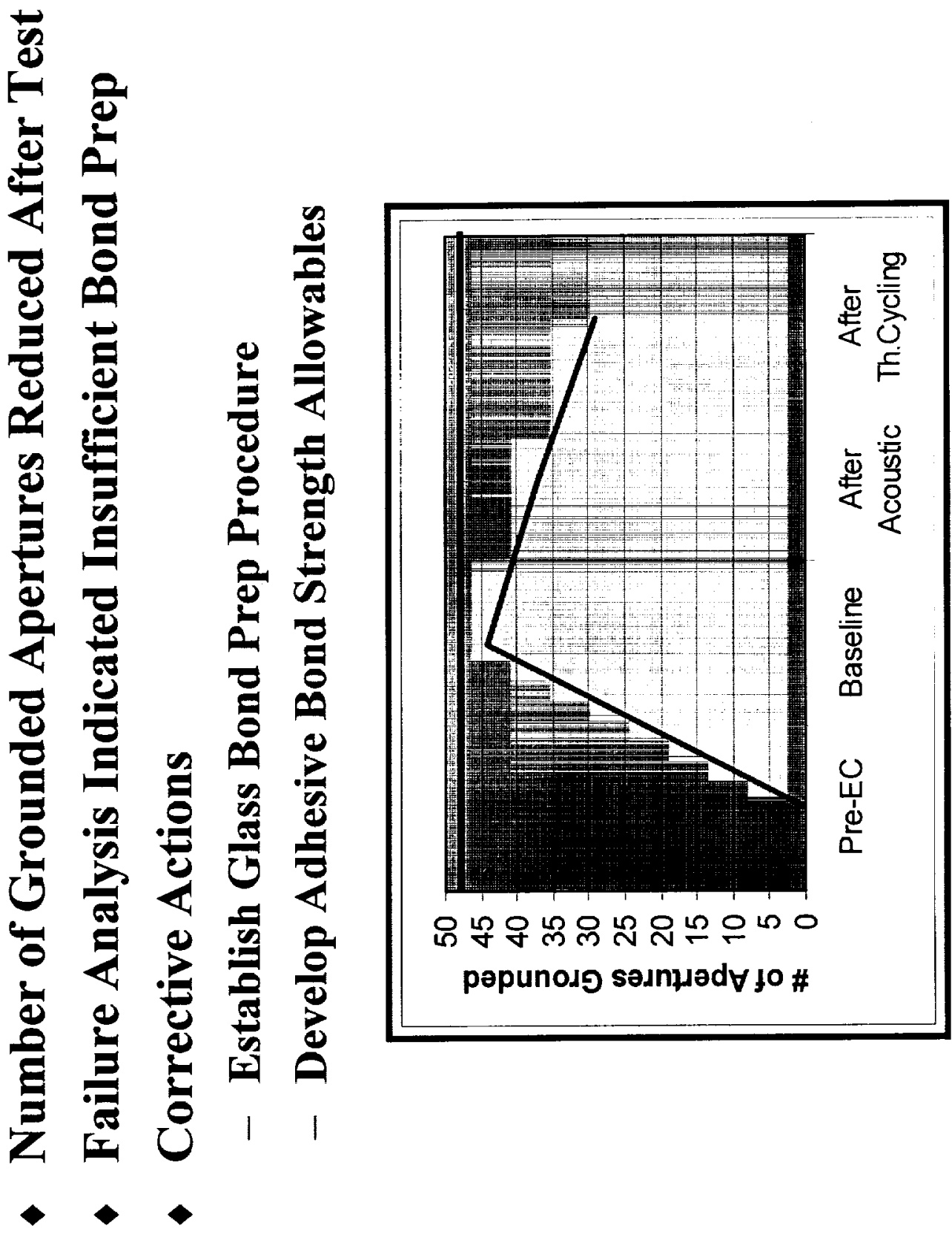

səมmฺnషS - IOD 

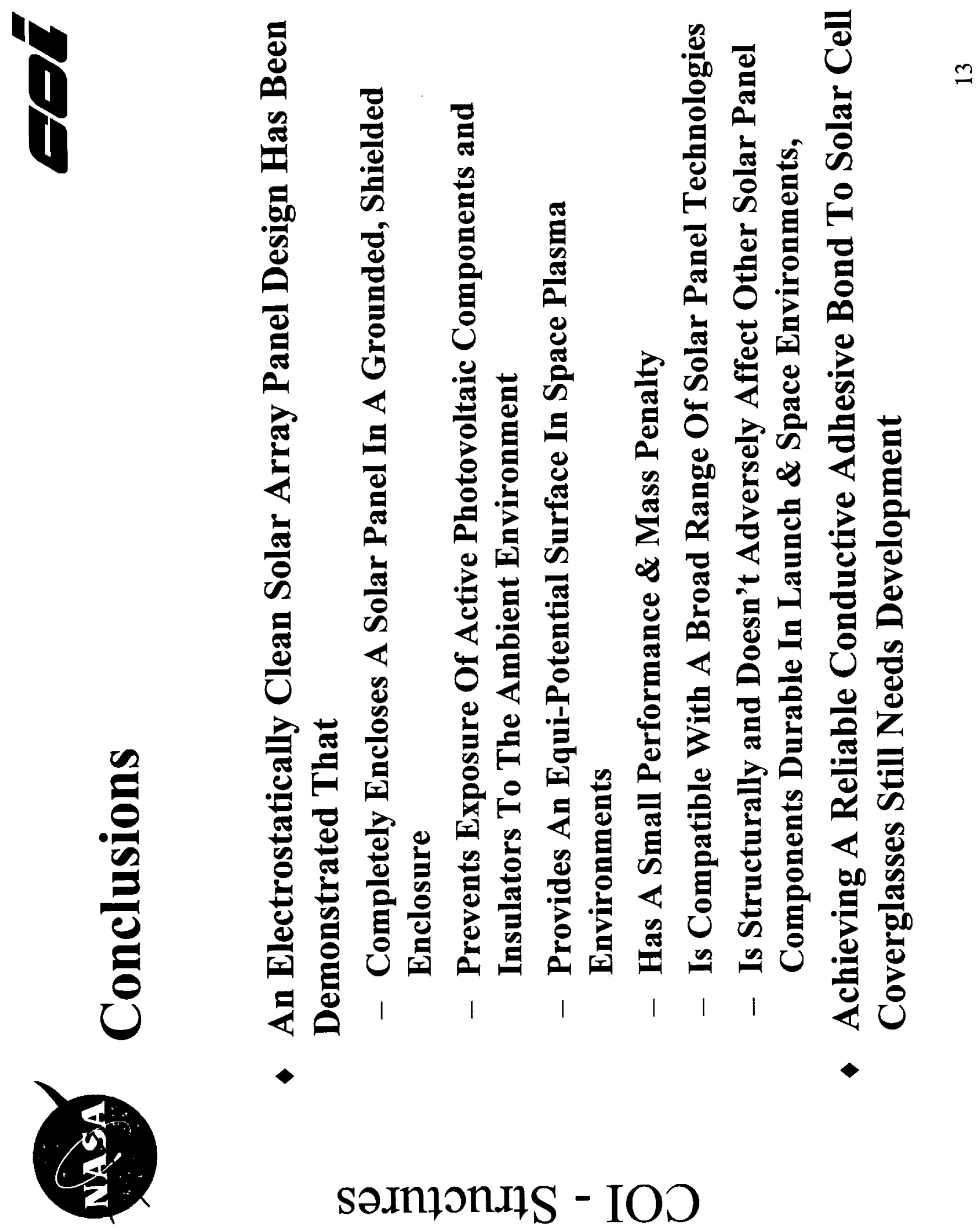


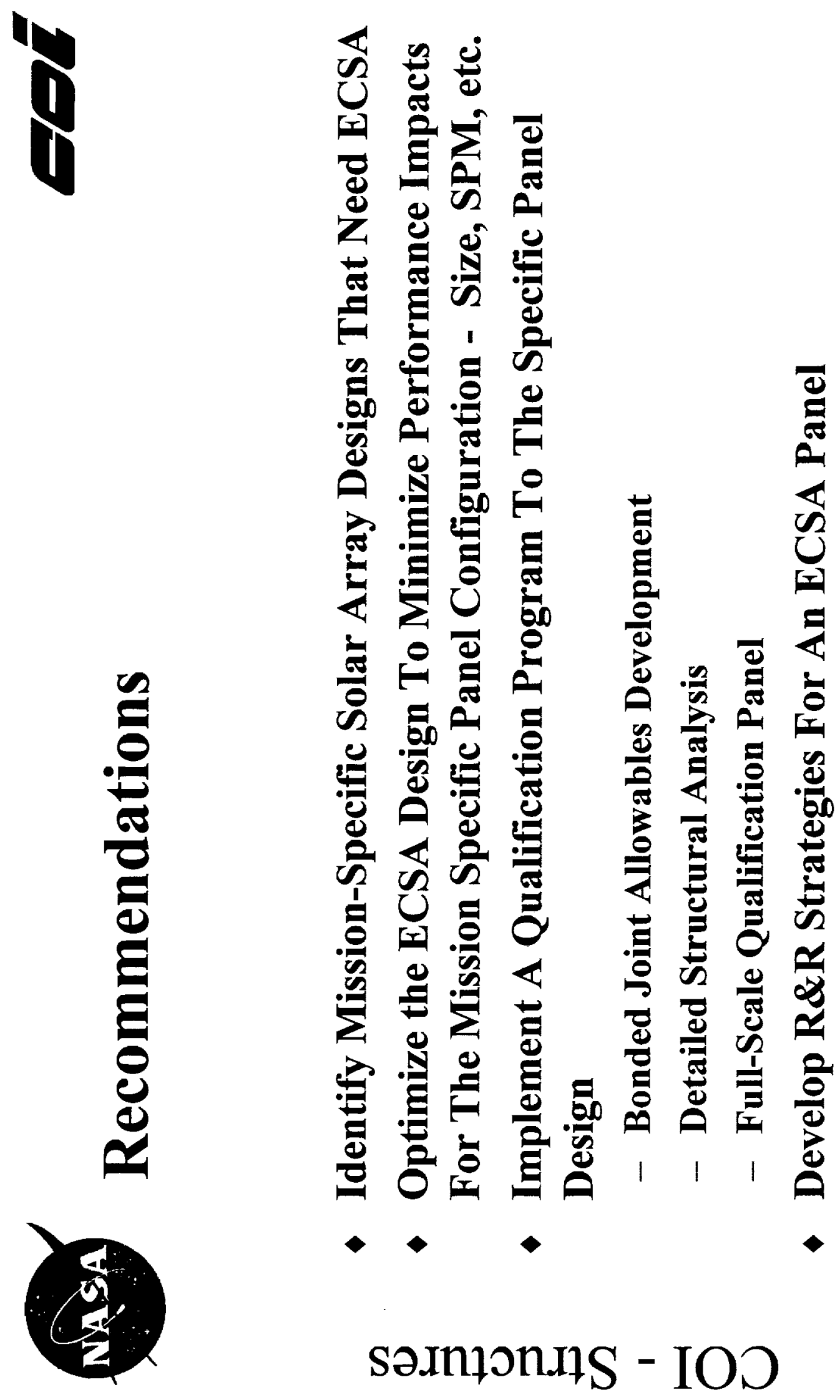

